some pages invites misunderstanding, and in these hurried days a certain amount of controlled skipping is legitimate. This difficulty could be overcome by a short summary at the end of each section or, preferably, each chapter so that the non-specialist could easily keep to the main channel of reasoning and not try to short-cut across the shoals.

The production is excellent and the many photographs beautifully clear.

W.H.H.A.

\section{THE BRAIN AND HUMAN BEHAVIOUR}

Edited by H. C. Solomon, M.D., Stanley CobB, M.D., and W. Penfield, M.D. Pp. xi $+{ }_{564}$, with 200 illustrations. London: Baillière, Tindall \& Cox Ltd. I958. I 20 .

Every year, one particular medical annual forms a milestone in the progress and a landmark in the literature of neuropsychiatry. This is the Research Publication of the Association for Research in Nervous and Mental Disease, now in its thirty-sixth volume. These works are quite incomparable, as the reviews of previous volumes appearing in these columns will testify: each highlights the tremendous advances made in one specific line of enquiry during twelve months' co-ordinated study by a number of topranking medical research departments. The research programme for 1956 , reported here, was centred upon the intriguing and challenging problem of relating brain and behaviour; scientists past and present, from the Ancient Philosophers to Contemporary Cyberneticists have given their best thoughts to this subject, in particular, to the body-mind relationship. The Programme Committee wisely decided that this aspect of the problem could well be omitted from the discussion, so that the final work presents an objective and scientifically rigorous account within the committee's terms of reference. A not inconsiderable portion of the work is necessarily based on animal studies, but in these only behaviour which is seen in the human is studied, and in each case a very direct relationship is made with clinical problems showing the same behavioural patterns.

The opening chapter immediately contradicts the aims of the programme, for in it Professor Lashley poses the question: 'What neurological characteristics constitute mind ?'. His answer, however, is strictly neurological, and if he writes with tongue in cheek and twinkle in the eye, he also gives the reader an inkling of the very deepest problems that confront neurology, leaving one in humorous indecisions as to whether man is merely a mosquito's mealticket or that lord of life, the animal with the highest glial index. Having broken the ice so provocatively, the following 20 papers get down to statistical brass tacks with concise but highly detailed accounts of experiments and clinical studies designed to throw light on the cerebral concomitants of behaviour patterns, and especially on localization. Studies of leucotomy give evidence of some functions of the frontal lobes; an excellent paper on the parietal lobes shows behaviour that follows destruction of part or whole of these lobes, but also provides some highly original positive data -in monkeys all lobes save the parietals were extirpated, and the resulting behaviour when compared with that following total cortical excision gives a very unequivocal account of exclusive parietal lobe function. The temporal lobe received the greatest number of independent studies, using electrical stimulation boch cortical and subcortical, and partial and total excision. Results in terms of psychological changes, memory defects, clinical and electrical responses, and other aspects of localization are discussed. Other focal studies include the deep sylvian areas, the periamygdaloid area, the speech area and the corpus callosum. Further papers provide a unified theory of cortical function, against a background of natural and synthetic pharmacology, neurophysiology, integrative stress reactions, and mental illness.

It is impossible in this brief space to even cover the contents, yet most of the contributions are worthy of a review independently. The work reported in these pages is executed in departments of long-standing and enviable reputation, the leaders of the research teams are international authorities on their subject; we can therefore accept their findings with confidence even if we do not always agree with their interpretations. That their statements range from the pontifical to the provocative is a healthy sign. We learn, we question, and we investigate .... and in doing so widen the boundaries of medical knowledge still further. It is often said of American medical literature that the quality suffers under the quantity: here in these volumes we have an annual reminder that American neuropsychiatric research is, at its best, unsurpassed in both.

\section{A PRIMER ON COMMON FUNCTIONAL DISORDERS}

By J. W. Fleming, M.D. Pp. xvi + I74. London: J. \& A. Churchill Ltd. $1958.36 \mathrm{~s}$.

This primer is directed essentially to the general practitioner. It deals with the patients he knows, and the symptoms that are presented in his surgery. More importantly, it gives a very detailed description of the therapeutic methods necessary in treating the psychosomatic disorders, methods which are tailor-made for the busy practitioner who has no time for frills and no special knowledge of psychiatry. At a time when a large number of publications on the subject are appearing, most of them characterized by extensive excursions into neurophysiology, this down to earth little manual written expressly for the man who in the first and last instance has to deal with such disorders is a real gem.

The early chapters cover the concepts and components of psychosomatic medicine, and provide in 
a straightforward and non-technical way the foundations for the practical instruction which follows. Next come the principles of therapy and management, with sensible and sometimes original forms of treatment, and then follows a discussion of the various syndromes, all treated separately and comprehensively-pathogenesis, symptomatology, differential diagnosis, treatment, and so on. Each chapter has a useful list of references, and the text is enlivened throughout by humorous illustrations. This is not the place to discuss the ethics of humour in medical texts, suffice it to say here that these drawings are not only in excellent taste, but would prove extremely useful if reproduced for the patients, and have been, in fact, included for this purpose.

This work is more than a manual, however useful it may prove in medical practice, for the author makes clear the dangers in extreme attitudes -not only the cautious but the over-enthusiastic. His explanation of the non-psychogenic functional disorders has an important place in psychosomatic literature, and his theories, though simple, make sense of much that appears complicated when stated in more wordy prose. Good reading for student and experienced clinician alike, this book is specially recommended to those just entering general practice.

\section{SKIN GRAFTING}

By James Barrett Brown, M.D. and Frank McDowell, M.D. Third Edition. Pp. xv + 4I I, with 328 illustrations, and six colour plates. London. Pitman Medical Publishing Co. Ltd. 1958. £5 5s.

This book, the third edition, is an expanded work based on 'Skin Grafting of Burns,' by the same authors, published in 1943, and an intermediate volume, 'Skin Grafting,' of 1949 . The enlargement from some 200 pages in the first edition, and 332 in the second, is brought about by several means.

The subject of burns is dealt with in all its aspects, and this section has been expanded in the light of modern developments. Other chapters have been enlarged, and fresh ones added, notably those concerned with trauma in civilian life, and radiation burns.

The student of Plastic Surgery will find this a useful and readable book, which does not burden him with too much operative detail. In one relatively short section pedicle flaps of all kinds are explained clearly, together with their uses, and their preparation. The use of local flaps, as opposed to distant tube pedicles, is rightly emphasized, and the authors constantly point out the desirability of completing a surgical programme in the minimum number of operations.

There is much of a repetitive nature, especially in the burns section, and many of the photographs and illustrations, some of them rather poor, do tend to split up the text unnecessarily, and cause the readêr constantly to search among pages already read for diagrams quoted in the pages following.

The use of homografts in the severely burned patient is explained, and helpful suggestions are made regarding the organization of post morte skin banks. This section, together with that diss cussing radiation burns, and like injuries, is a most interesting and valuable addition, which , coute become of great importance in a national emergenc.

In any subsequent edition improvements in the presentation of this work should produce a firsts class book out of what is, at the moment, a good one.

\section{SURGERY OF THE SYMPATHETIC NERVOUS. SYSTEM}

By Professor Sir James Paterson Ross, K.C.V.O

LL.D., M.S., F.R.C.S., F.R.A.C.S., F.A.C.S్ Third Edition. Pp. xii + 170, illustrated London: Baillère, Tindall \& Cox. 1958. 35\%

Twenty years ago Sir James Paterson Roş published the last edition of his book on the Surger of the Sympathetic Nervous System. A new edition after this lapse of time is most welcome This is a short book written by a master who, as result of long experience, knows what is important and what can be omitted. Surgeons will find that this is a monograph of great practical valug During the past decade sympathectomy has $\overline{6}$ sit much of its appeal, largely because it has bee performed too frequently and also on many un suitable patients. Sir James Paterson Ross corrects this impression and tells the surgeon the real valuog of this most useful operation.

\section{FUNGUS DISEASES AND THEIR TREATMENT}

Edited by R. W. RIDDELL, M.D.(Lond.), F.R.C.PS (Edin.), and G. T. STEWART, B.Sc., M.D.(Glas.) D.T.M. \& H. Pp. xvii $+256+$ index, illus trated. London: Butterworth \& Co. Ltd. 1958 45s.

Mycology is a neglected subject in this countryo We largely depend on American authors for ou textbooks and, while some of these are excellent and are based on wide experience, they tend $t \bar{\theta}$ leave a false impression of the frequency in thit country of the conditions described.

This book will help to restore a balanced poin of view at a time when the fungous diseases are growing in importance. It is not a true textbool nor a review; it is described by the publishers as work of reference but is, in fact, an edited serie of papers given in a symposium held at th Brompton Hospital in July 1957 . There are $2 \dot{2}$ articles on the pathology and epidemiology of the diseases and, in the second part, nine on treatment 